\title{
Ethical dilemmas in occupational therapy and physical therapy: a survey of practitioners in the UK National Health Service
}

\author{
Rosemary Barnitt University of Southampton, Southampton
}

\begin{abstract}
Objectives-To identify ethical dilemmas experienced by occupational and physical therapists working in the UK National Health Service (NHS). To compare ethical contexts, themes and principles across the two groups.

Design- $A$ structured questionnaire was circulated to the managers of occupational and physical therapy services in England and Wales.

Subjects-The questionnaires were given to 238 occupational and 249 physical therapists who conformed to set criteria.

Results-Ethical dilemmas experienced during the previous six months were reported by 118 occupational and 107 physical therapists. The two groups were similar in age, grade, and years of experience. Fifty of the occupational therapy dilemmas occurred in mental health settings but no equivalent setting emerged for physical therapy. Different ethical themes emerged between the two groups, with the most common in occupational therapy being difficult/dangerous behaviour in patients and unprofessional staff behaviour, and for physical therapists resource limitations and treatment effectiveness. No differences were found in the ethical principles used.

Conclusion-The ethical dilemmas reported by the therapists were primarily concerned with health care ethics, ${ }^{\prime}$ rather than the more dramatic ethics reported in much of the biomedical ethics literature. ${ }^{2}$

Differences were found between the two professional groups when ethical contexts and themes were compared but not when ethical principles were compared. This suggests that educators and researchers need to be aware of work settings and the interdisciplinary nature of employment as well as ethical principles held by individual therapists. (Fournal of Medical Ethics 1998;24:193-199)
\end{abstract}

Keywords: Ethical dilemmas; occupational therapy; physical therapy; professional ethics

\section{Introduction}

Little is known about the ethical dilemmas occupational therapists and physical therapists encounter at work. In contrast there is a substantial literature about medical dilemmas, ${ }^{34}$ and an increasing literature about nursing dilemmas. ${ }^{56}$ Recent studies have identified dilemmas with aspects particular to therapists. For occupational therapists these include the risky discharge of patients from hospital, resource limitations, and poor standards of care. For physical therapists these include effectiveness of therapy, conflict between the patients' wishes and professional judgment, and refusal of therapy. ${ }^{78}$ Without case material which reflects these realities it is difficult for professional organisations to produce ethical codes, for educators to prepare students for practice, and for clinicians to benefit from the experience of others. ${ }^{9}$

In practice the material to which therapists have access is primarily from biomedical and health care ethics literature. Case examples from such literature may be given little attribution other than "drawn from wider experience", "books", "personal experience", "stories told by nurses and their colleagues" and "cases reported by students" 10 or "adopted from published legal cases", "cases submitted by colleagues", "a news report" or "prepared for this volume". "The reader cannot know if the cases given are typical or atypical of most practitioners' experience, or so distorted by the need to design an example to illustrate a moral principle that there is little of use to the therapist. A number of case examples appear to be selected for their heroic or dramatic possibilities rather than for their relevance to the day-to-day general ethical problems which beset most health workers. ${ }^{12}$

Uncertainty about the relevance of case material in bioethics literature has gained some support from a study by Christakis and Feudtner in Philadelphia, which confirmed that cases described in 
the existing literature were of dubious relevance to medical students. ${ }^{13}$ These researchers asked 152 medical students in the final clinical year of training to describe ethical dilemmas they encountered at work. Results included: performing medical procedures in which the student was not skilled; being a "team player" and having concerns about how decision-making and responsibility were abused; getting close to patients who had confided social and emotional material to the student, and witnessing unethical behaviour.

Similar day-to-day issues were found in a study by Udén et al where nurses and doctors told different kinds of stories about ethical difficulties, suggesting that work tasks and professional philosophies of the two professions were different. For nurses, themes included a focus on health, previous experience, closeness to the patient, quality of life and being supported by colleagues. For doctors there was a focus on disease and scientific knowledge, distance from the patient, preserving life, and being on one's own. ${ }^{14}$

As none of the published studies included therapists, and as there was some evidence that differences in dilemmas and interpretation of dilemmas existed between professional groups, ${ }^{15}{ }^{16}$ the following study was carried out.

\section{Method}

A four-page questionnaire was designed, based on the results of a pilot study. ${ }^{7}$ There were three sections: 1) biographical data, 2) report of an ethical dilemma, and 3) ranking of ethical principles. Completed questionnaires were subject to three stages of analysis: first, a description of the respondents, second, content analysis of the dilemmas, and third, the collation of data related to ethical principles. Independent judges were used to enhance the reliability of the content analysis. ${ }^{17}$

\section{SAMPLING}

The physical therapy sample was obtained through a list of service managers supplied by the Chartered Society of Physiotherapy. These numbered 747. A similar list was not available for occupational therapy and was compiled from the job vacancy column of the professional journal, the register of the Occupational Therapists' Board, and telephone sampling using The Hospitals Year Book. ${ }^{18}$ The resulting sample numbered 714. From these prepared lists a one-in-three sample of therapy service managers was randomly selected. The final sample numbers were 238 occupational therapy and 249 physical therapy managers. Each of these was asked to give the questionnaire to a member of their staff who fittef the criteria given in an accompanying letter, the main one being "majority of time spent treating patients".

\section{PROCEDURE}

Subjects who had received the questionnaire we asked to write down the story of an ethical dilemma experienced at work during the previous six months. Questions were then asked about the setting and outcome of the dilemma, the peopte involved, decisions taken, and the period over which the dilemma ran. Subjects then allocated "their" story to a set of ethical principles provide్d in tabular form. These principles were then rankordered. Subjects were also asked to give biographical information including age, grade, ado years of experience.

\section{Results}

Questionnaires were returned by 361 therapis $\vec{\theta}$ 182 occupational therapists and 179 physical therapists, a $76 \%$ and $72 \%$ response rate respectively.

Of those returned, 52 occupational therapids and 61 physical therapists reported no ethicl dilemma in the past six months. A further 23 ga\&e limited information and were excluded from the analysis. This left 118 occupational therapists amd 107 physical therapists in the sample.

\section{SAMPLE DESCRIPTION}

The sample comprised 15 men and 199 women: whom $70 \%$ of the occupational therapists and $69 \%$ of the physical therapists were aged betwe 26 and 40 .

The time since qualification was 13 years or less for $67 \%$ of the occupational therapists and $52 \%$ f the physical therapists.

The majority of respondents were employed $\overline{\bar{a}}$ senior II, senior I or equivalent grades: $75 \%$ of the occupational therapists and $83 \%$ of the physigl therapists.

SETTING IN WHICH THE DILEMMAS OCCURRED Data was analysed by clinical specialty (table work setting and patient age band.

The most common work settings where the dilemmas occurred were community, $48 \%$, a d acute hospital, $31 \%$, for the occupational the pists, and primary health care, $28 \%$, and acuere hospital, $62 \%$, for the physical therapists.

The most common age bands where ethifal dilemmas were reported were with adult and eferly patients. 
Table 1 Clinical specialties where the dilemma occurred

\begin{tabular}{lcc}
\hline Clinical specialty & $\begin{array}{l}\text { Occupational } \\
\text { therapy }\end{array}$ & $\begin{array}{l}\text { Physical } \\
\text { therapy }\end{array}$ \\
\hline Mental Health & 50 & 4 \\
Learning Disability & 16 & 6 \\
Neurology & 17 & 18 \\
Respiratory & 2 & 23 \\
Orthopaedics & 5 & 15 \\
Surgical & 5 & 15 \\
Total S's & $101^{\star}$ & $102^{\star \star}$
\end{tabular}

${ }^{\star}$ Other categories with five or less responses were Cardiovascular and Oncology for occupational therapists.

$\star \star$ Other categories with five or less responses were Cardiovascular, Intensive Care, Oncology, and Obstetrics and Gynaecology for physical therapists.

\section{THEMATIC ANALYSIS OF STORIES}

The therapists' stories were analysed using content analysis. Reliability of the main themes identified by the researcher was tested by two independent judges. Agreement was found in $84 \%$ (Judge 1) and $91 \%$ (Judge 2) of the cases. The remaining cases were negotiated to agreement.

The themes identified in the therapists' stories are given in tables 2 and 3.

Quotations which illuminate the themes are given below. Some fit more than one theme, and where this is the case the example has been allocated to the dominant theme.

\section{OCCUPATIONAL THERAPY THEMES}

\section{Difficult or dangerous behaviour in patients}

"My client was a child who was severely mentally handicapped and his behaviour was causing serious difficulties in the family home, scratching, banging, tearing at family members and their pos-

\section{Table 2 Themes identified in occupational therapy $N=111$}

\section{Themes}

Number of

Difficult/dangerous behaviour in patients

instances

Unprofessional/incompetent staff

Lack of respect for vulnerable patients

20

Difficult/risky decisions about patient discharge

Unfair allocation/lack of resources

Lack of confidentiality/privacy for the patient

Lack of respect for the therapists' opinions

Total S's

Table 3 Themes identified in physical therapy $N=106$

\begin{tabular}{lc}
\hline Themes & $\begin{array}{l}\text { Number of } \\
\text { instances }\end{array}$ \\
\hline Unfair allocation/lack of resources & 30 \\
Treatment appropriateness/effectiveness & 27 \\
Unprofessional/incompetent staff & 16 \\
Not telling the truth & 15 \\
Lack of respect for the therapists' opinions & 11 \\
Difficult patients & 7 \\
Total S's & 106 \\
\hline
\end{tabular}

sessions. I provided a chair and harness to restrain him but I have major worries that this will be used as an easy way out for controlling him."

"We were aware that patients had sexual relationships with each other, and this presented difficulties when one patient became pregnant and we were supposed to be looking after her. We have also had some trouble with patients masturbating in inappropriate places, on one occasion the patient was arrested."

Examples were also given of patients with mental health problems who could not be discharged into the community because of public fear of their behaviour, and of patients with diagnoses of epilepsy, coronary heart disease and Parkinson's disease who insisted on driving cars, with resulting danger to members of the general public.

\section{Unprofessional or incompetent staff}

"The way the staff coped with patients they saw as troublesome was to leave them sitting in their own urine or faeces if they were incontinent, or delaying help in getting them to the lavatory if they were continent."

"The staff gossiped about the patients to each other, other patients and their relatives, and to any visitors within earshot. I minded more because the information they gossiped about often led to patients being labelled as difficult."

Examples were also given of staff who were incompetent due to alcohol or mental health problems, of elderly patients who were verbally or physically abused and of issues surrounding fair treatment of people who were "less" popular with staff.

\section{Lack of respect for vulnerable patients}

"The patient was walking round the ward and in public areas with a urine bag on a stand. Usual practice was for mobile patients to have a leg bag and I asked the ward for one but was told that they didn't have one and that the patient was too confused to know."

"Photographs were taken of patients with, I assume, the relatives' permission, and then used in publicity and for discussion groups. One of the photographs was of John who had died but no attempt was made to remove his photograph. In a reminiscence group I was tempted to say 'This is John and he died four months ago'."

Other issues included: patients and patients' relatives stealing personal possessions; lack of contraceptive advice to sexually active patients, mainly people with mental health problems or learning disabilities, and abortions "without any effort to gain consent". 
Difficult/risky decisions about patient discharge

Most of the examples in this theme were to do with discharge of elderly patients from hospital back to their own homes.

"This elderly lady had been falling a lot at home and since she came into hospital. Despite a careful assessment in hospital and a home visit, both of which concluded she was unsafe, the rest of the team decided she should be discharged. She fell the next day and fractured her femur."

"The patient was dementing and showed that she was not safe to live on her own when we carried out a home visit. However, my opinion was disregarded in favour of hers - she was re-admitted two days later."

Issues around discharge were influenced by resources available for support in the community, and the wishes and behaviour of relatives and carers. Several examples were given where relatives or carers did not want elderly people back home, but had not told the patient. In extreme cases locks had been changed on house doors, no one was in to receive the patient, or the patient was accepted home but confined to, or locked in, a room.

\section{PHYSICAL THERAPY THEMES}

\section{Unfair allocation or lack of resources}

The two main dilemmas revolved around the effect of general practice fundholding, and staff reductions in Trust hospitals, both of which could lead to services being withdrawn or restricted.

"In the wards where I work, I have to check if the patient has insurance or a fundholding general physician. If they do, they get priority treatment as this is part of the contract. In practice, because of limits on staff, the other patients don't receive physical therapy at all."

"A policy was instituted that all patients with certain conditions should be discharged within so many days. This was part of costed care packages. Discharge took place regardless of the patient's need for more treatment, or to a greater extent, their home circumstances."

In the cases given above, the respondents gave as their primary concern the delivery of poor services because of lack of money, staff, and to an extent, poor management of the service. This links in closely with the next category of dilemma.

\section{Treatment effectiveness}

The examples given dealt with patients receiving or not receiving effective treatment. While some of the examples link to resources, the issues emerging here were around: professional decisionmaking; whether treatment should be given or not; how much treatment should be given, a evidence that the treatment given would be effective.

"We spend time and resources on multiply handicapped children who will make mirfor progress at best, and never be independent. I reasonable to put valuable physical therapy resources here when the same effort would get several adults back home or back to work."

"I carried on treating a patient who was cleariy going to die, because I felt it was my duty as a physical therapist. When he did die I of wondered if I caused him unnecessary distress his last hours. Now I would leave the personinin peace."

\section{Unprofessional or incompetent staff}

$\omega$
$\dot{\omega}$
$\omega$
움

The common theme for this set of examples wăs of poor or dangerous treatment delivered by st other than the physical therapist. The dilemma was how the physical therapist should act to lingit the perceived damage.

"The doctor misdiagnosed the patient and asked for inappropriate treatment. Despite sevesal approaches he refused to change his opini Finally we had to advise the patient to get a secold opinion, which confirmed our view."

"In one of our units several of the staff verba防y abuse patients who are elderly and mentally Part of me hopes that the patients are to demented to notice, and part of me wants to get something done about it. We have approached the managers who don't want to know."

Other examples given of unprofessional behầंiour were refusal of treatment to patients who were in a research control group, racist remakjs about patients, and therapists who kept patients in

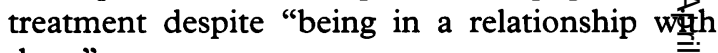
them".

\section{Not telling the truth}

The issues described here were mainly to do with giving patients their diagnosis and linked to thiss, whether the disease was life-threatening.

"The patient had a fracture but this was due to widespread cancer. I asked the genesol practitioner and the family if she could be told gigt they both refused. She was not allowed to prepđre for death with dignity which I feel is a respectal way to treat people."

"The patient had reached the stage where ghe couldn't swallow. His wife threatened to sue the hospital if any of us told him he was dying." 
Table 4 Principles used by occupational therapists and physical therapists

\begin{tabular}{llllll}
\hline & \multicolumn{2}{l}{ Frequency } & & \multicolumn{2}{c}{ Importance } \\
\cline { 2 - 3 } \cline { 6 - 6 } \cline { 5 - 6 } Principles & OT & PT & & OT & \multicolumn{1}{c}{$P T$} \\
& N rank & N rank & & N rank & N rank \\
\hline Justice: Patient & $72(1)$ & $76(1)$ & & $47(1)$ & $57(1)$ \\
Rights: Patient & $65(2)$ & $54(2)$ & & $30(2)$ & $27(2)$ \\
Doing harm/not & & & & & \\
$\quad$ preventing harm & $55(3)$ & $49(3)$ & & $29(3)$ & $21(4)$ \\
Rights: Staff & $46(4)$ & $45(4)$ & & $20(6)$ & $15(6)$ \\
Autonomy & $41(5)$ & $39(6)$ & & $25(4)$ & $22(3)$ \\
Justice: Staff & $35(6)$ & $44(5)$ & & $21(5)$ & $20(5)$ \\
Totals & 314 & 307 & & 172 & 162 \\
\hline
\end{tabular}

Occupational therapists $\mathrm{N}=114$.

Physical therapists $\mathrm{N}=103$.

\section{ALLOCATION TO PRINCIPLES}

Analysis of the dilemmas by ethical principle is shown in table 4 . The data allocation and ranking were carried out by the therapists themselves.

Additional principles used by five or fewer therapists were truth-telling, ${ }^{5}$ confidentiality ${ }^{3}$ and not doing good. ${ }^{2}$ Differences in frequency and importance between the occupational therapists and the physical therapists were not significant.

\section{Discussion}

The study clarified some of the ethical issues currently facing occupational and physical therapists in the United Kingdom health services. Dilemmas were primarily about day-to-day ethics rather than dramatic ethics. ${ }^{19}$ Therapists' dilemmas had more in common with those experienced by medical students, ${ }^{20}$ in community medicine ${ }^{21}$ and in nursing ${ }^{22}$ than the more widely reported medical topics such as end of life decisions. One reason for this may be that the relatively mundane field of health care ethics is not as interesting to the media as euthanasia, surrogacy, or genetic engineering. A second reason, identified by Caplan, Callahan and Haas $^{23}$ in a Hastings Center Report, was that in rehabilitation ethical problems were difficult to define and were "complex and elusive". This confirmed the earlier views of Thomasma and Pisaneschi ${ }^{24}$ who found that dilemmas encountered by allied health professionals were "extremely difficult everyday dilemmas" and the temptation was for medical ethicists to move "towards exotic cases".

The complexity of cases experienced by the therapists was evident. Decision-making often involved several participants, leading to the need for consensus before action could be taken. The potential to act as a single moral agent was limited. Therapists reported dilemmas which ran over long timescales, had no obvious start or finish, involved different participants at different times, and had repeated episodes. This is unlike many published cases where discrete stories, with few participants, and a clear beginning and ending, are in the majority. ${ }^{25} 26$

Differences emerged between the occupational and physical therapy samples when the contexts of the dilemma were considered. The most common setting for dilemmas in occupational therapy was mental health, with physical therapy being divided between respiratory, neurological, orthopaedic and surgical settings.

Stories about dilemmas in mental health included elderly people who were "confused" and those in the "early stages of dementia". Thus the category mental health was not coterminous with psychiatry. Similar categorisation issues appeared for physical therapists, with patients being allocated to the primary referral category, for example "chest physical therapy", despite having additional neurological or orthopaedic diagnoses.

Whilst there is a literature about ethical issues in neurology and surgery which is of relevance to physical therapists, literature on mental health for the occupational therapists is more difficult to find.

The literature which does exist is predominantly about people classed as "incompetent" for legal purposes, or those who exhibit dangerous behaviour. The needs of workers in mental health settings for information about other issues is poorly addressed. Exceptions include Block and Chodoff $^{27}$ who write about ethics in psychiatry, Hanley and Gilhooley ${ }^{28}$ who write about ethics and therapy for the elderly mentally ill, and Barker and Baldwin ${ }^{29}$ who write about ethical practice in mental illness, learning disability and the elderly.

It had been expected that occupational therapists would experience most dilemmas in long term, and physical therapists in shorter term, settings. In the event sixty-two per cent of the physical therapists gave dilemmas in acute settings as expected, however, occupational therapists gave only eight per cent of the dilemmas in long-stay settings. Reasons for limited use of the long-stay category included working across several services during the dilemma, and a current preoccupation with political correctness. Some therapists reported that they felt pressured to refer to "several acute episodes" for a single patient rather than describe it as "long term".

Apart from context, differences also arose between the therapists when the narratives were thematically analysed. Themes which were found in the occupational therapy sample only were: "dangerous patients"; "vulnerable patients"; "risky decision-making" and "confidentiality and privacy for the patient". Themes for the physical 
therapy sample only were: "treatment appropriateness and effectiveness", and "not telling the truth".

A theme which was found in both groups but which had a higher incidence in occupational therapy than physical therapy was "difficult patients". Physical therapists had as the most common theme "unfair allocation or lack of resources", while this accounted for half the number in occupational therapy. Both groups were similarly concerned about "unprofessional or incompetent staff" and a "lack of respect for the therapists' opinions".

In matters to do with incompetent staff, therapists were concerned about staff from other disciplines treating patients badly, but in addition physical therapists had a concern about other professionals carrying out "their" unique skills badly. On the subject of difficult patients the examples from physical therapists were mainly around patients who refused therapy; would not cooperate with therapy, or who made sexual comments and demands. For occupational therapists the examples were around restraint and control of dangerous behaviour and patients who were not able or willing to look after themselves. Sexual expression was raised by the occupational therapists with regard to the rights of people with learning disabilities and mental health problems.

Differences emerged about lack of resources, with the occupational therapists having concerns about aids, equipment and services for people being discharged to, or living in the community; while the physical therapists were concerned about the impact of fundholding general practices on the level of service being offered. Both professions were concerned about the reduction of services and staffing due to cost constraints throughout the health service.

No differences emerged between the two therapist groups when use of ethical principles was compared, with the two highest ranks for both being "justice for the patient" and "rights of the patient".

Methodologically, a number of limitations were found in this study. First, the nature of the written story limited the amount of material which was given. Second, in allowing the subjects to carry out the analysis of the story and allocation to ethical principles validity may have been improved but reliability compromised. ${ }^{30}$ No equivalent research could be found in which research subjects categorised their own ethical dilemma material.

\section{Conclusion}

When ethical dilemma stories experienced by 118 occupational therapists and 107 physical thera- pists were analysed by principle, no differen帠s emerged, however, when the context of dilemma and the emergent themes were compared differences did emerge between the groups. This was partly explained by the differe्ष्तt types of patients, professional skills, and settirirss in which the therapists worked.

In view of these results it can be suggested that research into ethical practice in health care showild integrate data about principles held by the mo agent, with data about the practice setting in which ethical dilemmas emerge. If data abojit moral principles only is collected, the possibilitysof assuming that normative ethical theory is supported is high, that "all acceptable moral stanards of every time and place, can be rationally ordered and explained by reference to some setæif fundamental principles". ${ }^{31}$ In contrast if data about ethical dilemma contexts only is collected d, the possibility of assuming that non-normative contextual ethical theory is supported is high, that "in medical ethics, most of the real work of resolving moral problems occurred at the level $\bigotimes_{\infty}$ interpretation and comparison of cases". ${ }^{32}$

Therapists and other health care workers have little time to address the complex debates betwe nn these two schools of thought, and there is a ne्ged for literature and case material which reflects realities of practice.

Rosemary Barnitt, PhD, MSc, BSc, is Reader in the School of Occupational Therapy and Physiothera需y, University of Southampton, Highfield, Southamptgn.

\section{References}

1 Seedhouse D. Ethics: the heart of health care. Chichester: Wiley, 1988.

2 Beauchamp TL, Childress JF. Principles of biomedical ethics 5 th ed]. New York: Oxford University Press, 1993.

3 Ackerman TF, Strong C. A casebook of medical ethics. New York Oxford University Press, 1989.

4 Fry J, ed. Common dilemmas in family medicine. New Jerisy: George A Bogden and Son Inc, 1983.

5 Elander G, Drechsler K, Persson K. Ethical dilemmas in fong term care settings: interviews with nurses in Sweden and England. International fournal of Nursing Studies 1993;30(1) 1 7 . 6 Thompson IE, Melia KM, Boyd KM. Nursing ethics [3rd $\underbrace{\text { Edinburgh: Churchill Livingstone, } 1994 \text {. }}_{\text {fd] }}$

7 Barnitt RE. What gives you sleepless nights? Ethical practieg in occupational therapy. British fournal of Occupational Therapy
$1993 ; 56(6): 207-12$.

8 Barnitt RE. Deeply troubling questions: the teaching of ethics in undergraduate courses. British fournal of Occupational Therepy 1993;56(12):401-6.

9 Dimmitt JH, Artnak KE. Cases of conscience: casuistic anafsis of ethical dilemmas in expanded role settings. Nursing ERics 1994;1(4):200-7.

10 Kanne M. Professional nurses should have their own ethics current status of nursing ethics in the Dutch curriculum. Norsing Ethics 1994;1(1):25-33.

11 See reference 2: 403, 407-8, 414.

12 See reference 1: 20.

13 Christakis DA, Feudtner C. Ethics in a short white coat the ethical dilemmas that medical students confront. Acadestic Medicine 1993;68(4):249-54. 
14 Udén G, Norberg A, Lindsett A, Marhaug V. Ethical reasoning in nurses' and physicians' stories about care episodes. fournal of Advanced Nursing 1992;17:1028-34.

15 Barnitt RE. Truth telling in occupational therapy and physiotherapy. British fournal of Occupational Therapy 1994; 57(9):334-9.

16 Purtilo R. Ethical issues in teamwork. Archives of Physical Medicine and Rehabilitation 1988;69(5):318-26.

17 Robson C. Real world research. Oxford: Blackwell, 1993:272-85.

18 Robertson L, ed. The IHSM health and social services year book 1994/5. London: Institute of Health Services Management, 1995.

19 Francoeur R. Biomedical ethics. New York: John Wiley, 1983.

20 See reference 13: 252

21 See reference $4: 11$.

22 See reference 6: 75-82, 91-104, 111-22.

23 Caplan AL, Callahan D, Haas J. Ethical and policy issues in rehabilitation medicine. Hastings Center Report [spec supp] 1987;Aug:1-20.
24 Thomasma DC, Pisaneschi JI. Allied health professionals and ethical issues. Fournal of Allied Health 1977;Summer:15-20.

25 Purtilo RB. Ethical dimensions in the health care professions [2nd ed]. Philadelphia: WB Saunders, 1993.

26 Bailey DR, Schwartzberg SL. Ethical and legal dilemmas in occupational therapy. Philadelphia: F A Davis, 1995.

27 Block S, Chodoff P, eds. Psychiatric ethics. Oxford: Oxford University Press, 1984

28 Hanley I, Gilhooley M, eds. Psychological therapies with the elderly. London: Croom Helm, 1986.

29 Barker PJ, Baldwin S, eds. Ethical issues in mental health. London: Chapman and Hall, 1991.

30 Reason P, Heron J. Co-operative inquiry. In: Smith JA, Harré R, Langenhove LV, eds. Rethinking methods in psychology. London: Sage Publications, 1995.

31 Winkler ER, Coombs JR, eds. Applied ethics. Oxford: Blackwell, $1993 ; 2$.

32 See reference $31: 3$.

\section{News and notes}

\section{Ethics and Genetics}

The International Programme in Bioethics Education and Research is organising an Advance European Bioethics Course on Ethics and Genetics which will be held from 19-21 November this year in Nijmegen, the Netherlands.

Subjects will include: Ethics and the Human Genome Project; Genetic counselling, and Genetic screening.
For more information please contact: B Gordijn, $\mathrm{PhD}$, Catholic University Nijmegen, 232 Dept of Ethics, Philosophy and History of Medicine, PO Box 9101, 6500 HB Nijmegen, the Netherlands. Telephone: 0031-24-3615320; fax: 0031-24-3540254; internet site: http//www.azn.nl/fmw/news.htm E-mail: b.gordijn@ efg.kun.nl

\section{News and notes}

\section{Competition}

The Student Interest Group of the American Society for Bioethics and the Humanities (formerly the Society for Health and Human Values), is sponsoring a call for student-written papers on subjects related to the medical humanities and bioethics. The winner will receive a $\$ 1,000$ award and will be expected to present the paper at the $1998 \mathrm{ASBH}$ annual meeting in Houston, Texas, November 17-22.
Papers must be received by July 3,1998 .

For further information please contact: Alexandra Bambas, Institute for the Medical Humanities, Suite 2.210, Ashbel Smith Building, Galveston,TX 775551311. Telephone: 409/737-4012; e-mail: abambas@ marlin.utmb.edu 